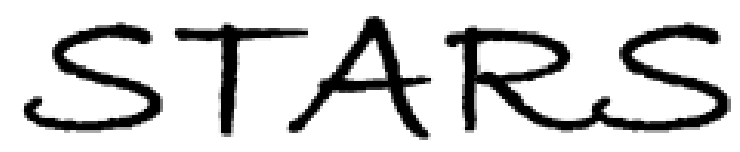

University of Central Florida

STARS

$1-1-2009$

\title{
Comparative Data Mining Analysis for Information Retrieval of MODIS Images: Monitoring Lake Turbidity Changes at Lake Okeechobee, Florida
}

\author{
Ni-Bin Chang \\ University of Central Florida \\ Ammarin Daranpob \\ University of Central Florida \\ Y. Jeffrey Yang \\ Kang-Ren Jin
}

Find similar works at: https://stars.library.ucf.edu/facultybib2000

University of Central Florida Libraries http://library.ucf.edu

This Article is brought to you for free and open access by the Faculty Bibliography at STARS. It has been accepted for inclusion in Faculty Bibliography 2000s by an authorized administrator of STARS. For more information, please contactSTARS@ucf.edu.

\section{Recommended Citation}

Chang, Ni-Bin; Daranpob, Ammarin; Yang, Y. Jeffrey; and Jin, Kang-Ren, "Comparative Data Mining Analysis for Information Retrieval of MODIS Images: Monitoring Lake Turbidity Changes at Lake Okeechobee, Florida" (2009). Faculty Bibliography 2000s. 1403.

https://stars.library.ucf.edu/facultybib2000/1403

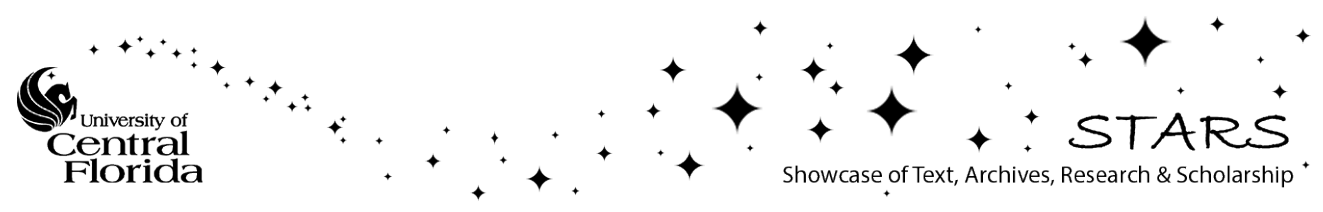




\title{
Comparative Data Mining Analysis for Information Retrieval of MODIS Images: Monitoring Lake Turbidity Changes at Lake Okeechobee, Florida
}

\author{
Ni-Bin Chang ${ }^{a}$, Ammarin Daranpob ${ }^{a}$, Y. Jeffrey Yang ${ }^{b}$, and Kang-Ren \\ Jin $^{\mathbf{c}}$ \\ ${ }^{a}$ Department of Civil and Environmental Engineering, University of Central Florida, Orlando, \\ Florida, USA \\ nchang@mail.ucf.edu and ammarin r@hotmail.com \\ ${ }^{b}$ U.S. EPA, National Risk Management Research Laboratory, Water Supply and Water \\ Resources Division, Cincinnati, Ohio, USA \\ kjin@sfwmd.gov \\ ${ }^{\mathrm{c}}$ Hydrologic \& Environmental Systems Modeling Division, South Florida Water Management \\ District, West Palm Beach, Florida, USA \\ Yang.Jeff@epamail.epa.gov
}

\begin{abstract}
In the remote sensing field, a frequently recurring question is: Which computational intelligence or data mining algorithms are most suitable for the retrieval of essential information given that most natural systems exhibit very high non-linearity. Among potential candidates might be empirical regression, neural network model, support vector machine, genetic algorithm/genetic programming, analytical equation, etc. This paper compares three types of data mining techniques, including multiple non-linear regression, artificial neural networks, and genetic programming, for estimating multi-temporal turbidity changes following hurricane events at Lake Okeechobee, Florida. This retrospective analysis aims to identify how the major hurricanes impacted the water quality management in 20032004. The Moderate Resolution Imaging Spectroradiometer (MODIS) Terra 8-day composite imageries were used to retrieve the spatial patterns of turbidity distributions for comparison against the visual patterns discernible in the in-situ observations. By evaluating four statistical parameters, the genetic programming model was finally selected as the most suitable data mining tool for classification in which the MODIS band 1 image and wind speed were recognized as the major determinants by the model. The multi-temporal turbidity maps generated before and after the major hurricane events in 2003-2004 showed that turbidity levels were substantially higher after hurricane episodes. The spatial patterns of turbidity confirm that sediment-laden water travels to the shore where it reduces the intensity of the light necessary to submerged plants for photosynthesis. This reduction results in substantial loss of biomass during the post-hurricane period.
\end{abstract}

Keywords: turbidity, water quality, remote sensing, MODIS, data mining, lake management.

\section{INTRODUCTION}

Lake Okeechobee, Florida, is the second largest freshwater lake wholly located in the U.S. Because of its shallow depth, hurricanes with strong winds may stir up bottom mud into the water column. Turbidity reflecting the level of particulates (e.g., plant debris, clay, and silt) in the water column is often measured to assess the clarity of the water, which is consistent with the total suspended solids (TSS) in water quality management. Therefore, spatiotemporal variations of turbidity in the water column are an important factor influencing dynamic 
patterns of species abundance, composition and biological mechanisms. Much of the excess phosphorus from the inflow of the lake has been sequestered in the sediments for decades and released primarily as available phosphorus through diffusion and resuspension from the sediment contributing to more TSS [1][2]. Study of the complex interactions between sediment dynamics and the ecological integrity of the Lake Okeechobee watershed is recognized as a key to the success of water quality management. Sediment-water interactions, including diffusive fluxes and sediment re-suspension, are a source of available phosphorus for phytoplankton, causing algal blooms and uncontrolled growth of submerged plants when the turbidity is not sufficiently high to hinder light penetration.

Generally, such multitemporal and spatial patterns of turbidity are not easily retrieved by limited in-situ observations but, potentially, they can be acquired using satellite imagery if the repeat time is short at a reasonable spatial resolution. This potential can be realized through the recent advances in remote-sensing technologies using the empirical regression to retrieve Landsat Multi-Spectral Scanner (MSS) [3], the Advanced Very High Resolution Radiometer (AVHRR) [4], Landsat Thematic Mapper (TM) [5]. For example, a neural network model was derived for estimating sea surface chlorophyll and sediments from Landsat-TM imagery [6]. Comparative analyses between Landsat - TM5 and SPOT-HRV were conducted for monitoring total suspended matter [7]. The band combination of the Moderate Resolution Imaging Spectroradiometer (MODIS) Terra and ENVISAT Medium Resolution Imaging Spectrometer (MERIS) instruments for operational monitoring of lakes and coastal waters was conducted successfully [8]. Recently, an Airborne Imaging Spectrometer for Applications (AISA) data was spectrally averaged corresponding to ENVISAT MERIS channels for classification of three water quality variables: Secchi depth, turbidity, and chlorophyll-a (hereafter referred to as chl-a) [9]. Water clarity or turbidity in Tampa Bay, Florida, using the Sea-viewing Wide Field-of-View Sensor (SeaWiFS) satellite imagery was performed and compared against the Secchi Disk Depth (SDD) [10], which was actually a companion study using MODIS/Aqua 250-m imagery in Tampa Bay, Florida [11]. A six-year SeaWiFS retrospective view in Chesapeake Bay using SeaWiFS also shows that satellitebased observations are useful for inferring TSS concentrations in estuarine areas [12].

This paper evaluates three data mining techniques for retrieval of Moderate Resolution Imaging Spectroradiometer (MODIS) Terra 8-day composite imageries with $500 \mathrm{~m}$ resolution for monitoring turbidity changes in Lake Okeechobee during and after the hurricanes Frances and Jeanne in 2004. These algorithms, including multiple nonlinear regression (MNR), artificial neural networks (ANN), and genetic programming (GP), for the robust contentbased retrieval of multispectral satellite images, however, are not those physics-based invariant theoretical representations.

\section{BACKGROUND}

\subsection{Sources of in-situ data}

"DBHYDRO" is the hydrometeorologic, water quality, and hydrogeologic data system developed and maintained by the South Florida Water Management District (SFWMD). To produce DBHYDRO, the District participates in a cooperative program with other agencies, such as the U. S. Geological Survey, Everglades National Park, the U.S. Army Corps of Engineers, Lake Worth Drainage District, and the U.S. Department of Agriculture. DBHYDRO allows users to access over 30,000 station-years of data, collected over 6,000 stations in and around the District. Water quality at the lake has been monitored monthly since 1972. Twenty four monitoring stations have been deployed and maintained by the SFWMD. Figure 1 shows the locations of twenty four monitoring sites at Lake Okeechobee for which the wind speed, water level, air temperature, and rainfall data are available in the DBHYRO database. For example, on $12^{\text {th }}$ March 2003, turbidity measurements were carried 
out at KBAR, L001, L002, L003, L004, L005, L008, LZ40, LZ42N, POLEOUT and STAKEOUT sites. These efforts are considered essential for estimation of turbidity levels around the Lake.

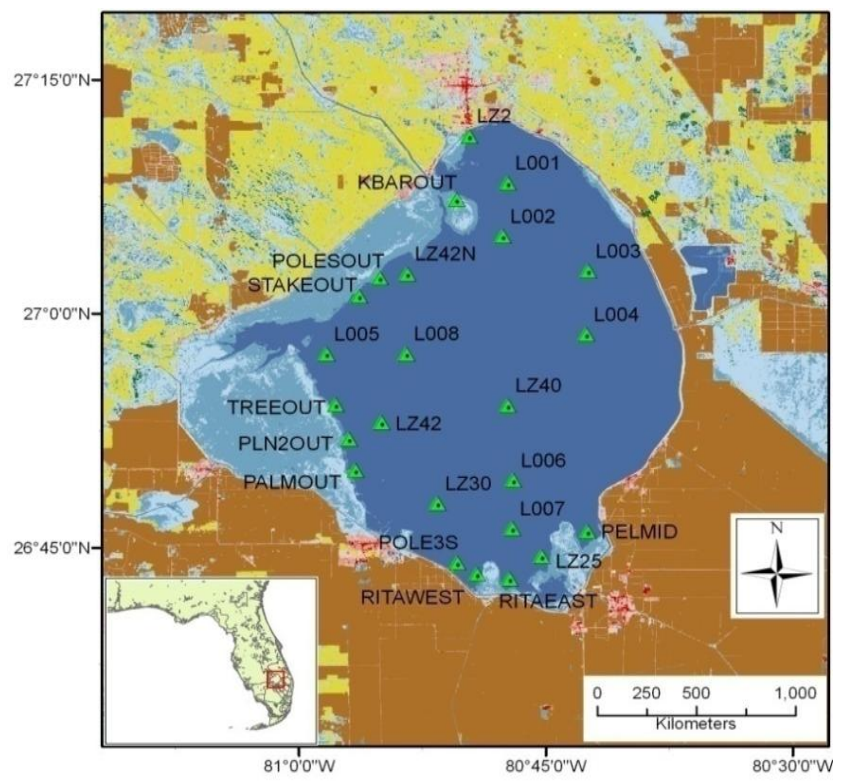

Fig. 1. Environmental data collected at 24 stations located throughout Lake Okeechobee.

\subsection{Hurricanes and their impacts on Lake Okeechobee}

Lake Okeechobee is a large, shallow, eutrophic lake located in south central Florida along the pathway of several major hurricanes. The Lake is the second largest freshwater lake entirely within the United States and covers a surface area of 1800 square $\mathrm{km}$ ( 730 square miles), with an average depth of $2.7 \mathrm{~m}$ ( 9 feet). As the central part of a larger interconnected aquatic ecosystem in south Florida and as the major surface water body of the Central and Southern Florida Flood Control Project, Lake Okeechobee provides a number of societal and environmental service functions including water supply for agriculture, urban areas, and the environment. In such a shallow, mud-bottom lake, hurricanes could potentially play a major role in ecosystem dynamics, even for the weakest Category-I storms with winds from 118 to $152 \mathrm{~km} / \mathrm{h}$ (74 to $95 \mathrm{mph}$ ). These impacts may destroy cohesive layers of mud, re-suspend Prich sediment particles, increase turbidity, and/or defoliate submerged aquatic vegetation (SAV). Figure 2 shows the long-term interactions between turbidity and total phosphorus in Lake Okeechobee according to all observations collected. 


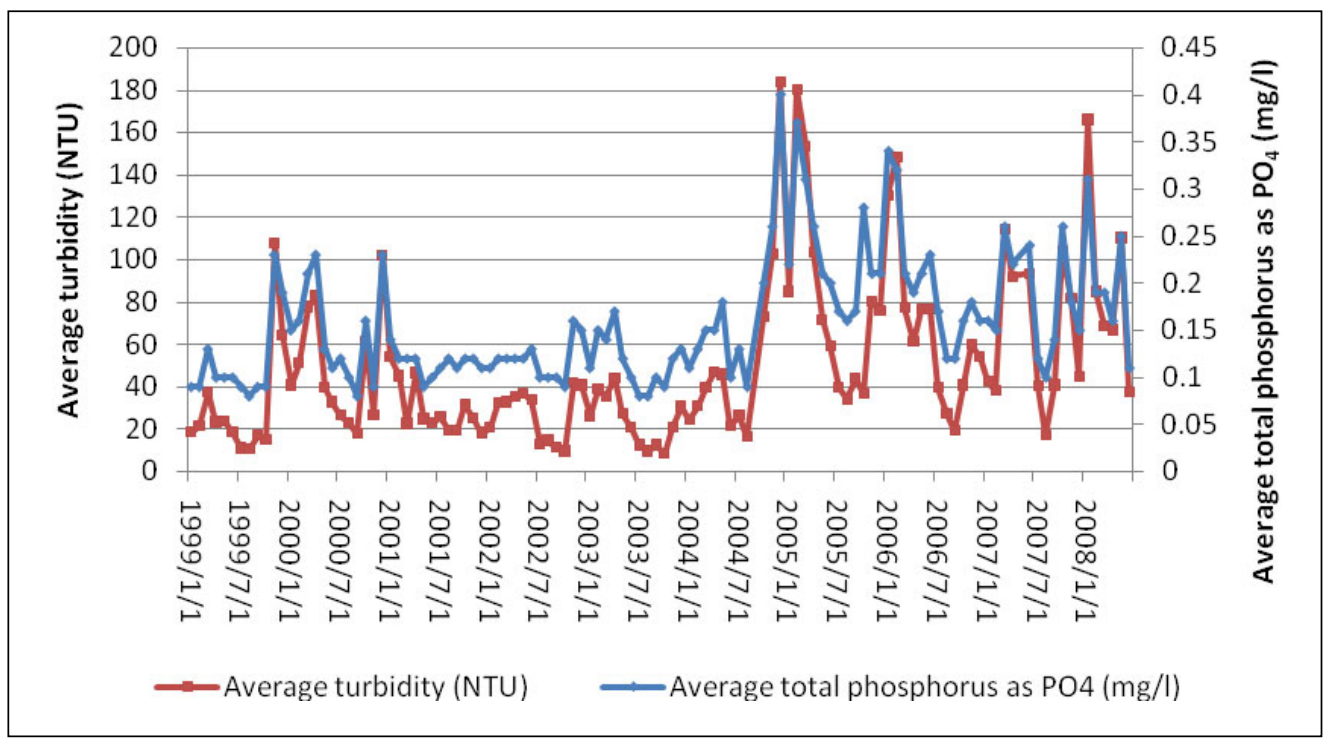

Fig. 2. Long-term interactions between turbidity and total phosphorus in Lake Okeechobee

\subsection{MODIS data}

MODIS is a key instrument aboard the Terra (EOS AM) and Aqua (EOS PM) satellites. Several studies have demonstrated the potential of MODIS satellite data to monitor water quality in coastal and estuarine waters. Table 1 illustrates the MODIS channels on $250 \mathrm{~m}$ and $500 \mathrm{~m}$ and their potential applications. The file contains the same seven spectral bands of data as the daily file. It also has an additional six bands of information concerning quality control, solar zenith, relative azimuth, surface reflectance $500-\mathrm{m}$ state flags, and surface reflectance day of year.

Table 1. MODIS bands on $250 \mathrm{~m}$ and $500 \mathrm{~m}$ images and their parameters

\begin{tabular}{|c|c|c|c|}
\hline Band & $\begin{array}{c}\text { Pixel Resolution } \\
(\mathrm{m})\end{array}$ & $\begin{array}{c}\text { Reflected } \\
\text { Bandwidth } \\
\text { range(nm) }\end{array}$ & Potential applications \\
\hline 1 & 250 & $620-670$ & $\begin{array}{c}\text { Absolute Land Cover } \\
\text { Transformation, Vegetation } \\
\text { Chlorophyll } \Pi\end{array}$ \\
\hline 2 & 250 & $841-876$ & $\begin{array}{c}\text { Cloud Amount, Vegetation } \\
\text { Landcover Transformation }\end{array}$ \\
\hline 3 & 500 & $459-479$ & Soil/ Vegetation Difference \\
\hline 4 & 500 & $545-565$ & Green Vegetation \\
\hline 5 & 500 & $1230-1250$ & Leaf/ Canopy Differences \\
\hline 6 & 500 & $1628-1652$ & Snow/ Cloud Differences \\
\hline 7 & 500 & $2105-2155$ & Cloud Properties, Land Properties \\
\hline
\end{tabular}

MODIS band 1 at $250 \mathrm{~m}$ is $620-670 \mathrm{~nm}$ and is suited to the measurement of suspended sediment concentrations, whereas the bands 3 and 4 at $500 \mathrm{~m}$, which have spectral ranges of $459-479 \mathrm{~nm}$ and 545-565 nm, respectively are applicable for chl-a estimates [13]. But MODIS 250-m bands have no eight-day composite images and Florida is a region with significant and rather persistent cloud impact. Therefore, in this study, Surface Reflectance 
eight-Day L3 Global 500-m MODIS satellite images were used for developing a turbidity map of Lake Okeechobee. This file is a composite file containing eight consecutive daily 500$m$ images in which the "best" observation during each eight-day period, for every cell in the image, is retained. This helps reduce or eliminate clouds from a scene. Finally, 23 cloud-free images were downloaded at a frequency of one image per month in 2003 and 2004. Table 2 shows a summary of those MODIS images finally selected and used in the study.

Table 2. The date of MODIS images selected for use in the study

\begin{tabular}{|l|l|l|l|l|l|l|l|l|l|l|l|}
\hline & Jan. & Feb. & Mar. & Apr. & May & Jun. & Jul. & Aug. & Sep. & Oct. & Nov. \\
\hline 2003 & & & 13 & 01,16 & 06 & 10 & 15 & 26 & 08 & 13 & 12 \\
\hline 2004 & 06,22 & 03 & 16 & 19 & 17 & 08,09 & 07,20 & 09 & & 11 & 17 \\
\hline
\end{tabular}

\section{METHODOLOGY}

\subsection{Data mining}

Data mining is a technique frequently used to discover the patterns and relationships of physical variables. This technique has shown promise for analysis and prediction in multiple disciplines, bringing together other techniques from database, machine learning, statistics and pattern recognition to address information retrieval from larger databases [14][15]. Traditionally, statistical (empirical) approaches based on regression analysis have received more attention in the recent past. From early attempts using simple multiple linear regression (MLR) to more sophisticated recent applications, MLR has proven to be an effective tool for quick prediction. Moreover, it has been demonstrated that even highly complex and nonlinear ecological time series can be quantified for predictions using multiple non-linear regression (MNR), artificial neural networks (ANN) and genetic programming (GP). ANN may classify or predict data with noise by minimizing the root mean square error [16][17]. On the other hand, GP has the advantage of evolving functions and rules and applies an evolutionary learning algorithm to discover predictive rules for population dynamics [18]. It may also reveal which parameters are the most important factors for determining the turbidity in the Lake from which the model with the best performance may be selected to generate such turbidity maps.

\subsection{Models}

\subsubsection{Multiple Nonlinear Regression (MNR) Model}

Non-linear regression is a general technique for fitting data. It fits data to any equation that defines $\mathrm{Y}$ as a function of $\mathrm{X}$ and one or more parameters. It finds the value of those parameters that generate the linear or non-linear regression curve that comes closest to the available data. In the past, methods that are frequency-domain-oriented and dependent on the properties of Finite Fourier Transforms (FFT) were introduced in which the Grenander and Rosenblatt's conditions were introduced for making certain assumptions about the regressor variables [19]. The conditions change with the nature of non-linearity of the parameters in the regression variables. If the nonlinear parameters to be estimated are frequencies, one has to impose a different set of conditions, even though the model looks linear [19]. In this study, the non-linear regression coefficients were determined by using SPSS ${ }^{\circledR}$ software. The 2003 and 2004 data were used for model construction. The equation (1) was formulated using ground truth turbidity, wind speed, water level, rainfall, air temperature, and MODIS 500-m bands 17. Turbidity data were used as the dependent variable in the MNR analysis. Note that the same input variables were applied for both of the GP and ANN models. 
Turbidity $=\mathrm{a}_{0}+\mathrm{a}_{1} \times \mathrm{b} 1+\mathrm{a}_{2} \times \mathrm{b} 1^{3}+\mathrm{a}_{3} \times \mathrm{b} 2 \div\left(\mathrm{a}_{4}+\mathrm{b} 2\right)+\mathrm{a}_{5} \times \mathrm{b} 3 \div\left(\mathrm{a}_{6}+\mathrm{b} 3\right)+\mathrm{a}_{7} \times \mathrm{b} 4 \div\left(\mathrm{a}_{8}+\mathrm{b} 4\right)+\mathrm{a}_{9} \times \mathrm{b} 6 \div\left(\mathrm{a}_{10}+\right.$ b6) $+a_{11} \times$ temp $\div\left(a_{12}+\right.$ temp $)+a_{13} \times$ wind $\div\left(a_{14}+\right.$ wind $)+a_{15} \times$ level $\div\left(a_{16}+\right.$ level $)$

where $a_{i}$ are the regression coefficients; bi are MODIS bands; bi stands for MODIS band I imagery; level stands for the water level; temp represents the air temperature; and wind stands for the wind speed.

\subsubsection{Artificial Neural Networks (ANN) Model}

ANN models are versatile non-linear models that can deal with forecasting issues based on non-seasonal or seasonal time series. The most important capability of ANN models is their flexibility in dealing with any type of non-linear pattern without the prior assumption of the underlying data generating processes. The application of ANN models for the estimation of chlorophyll-a and sediments in coastal waters using remote sensing were proven to be effective [20][21]. In this study, the neural networks module in STATISTICA ${ }^{\circledR}$ was applied for handling the data mining work [22]. The ANN model used here has a three-layer structure, including one input layer, one hidden layer, and one output layer, which belongs to the feed-forward back-propagation (multi-layer perceptron) type, containing a basis neuron in each layer and a single neuron in the output layer. A sigmoid transfer function was employed in all neurons and weight adjustment was performed according to the generalized delta rule. Connection weights were initialized random values.

Models were constructed using the training subset of data. The validation subset (i.e., unseen dataset) was then used to provide an indication of model performance. All generated descriptors were included in the initial model. The ANN program applied here also utilizes regularization and search algorithms for automated descriptor selection. Redundant descriptors were then pruned and the system was re-trained. Once optimum models were achieved, true predictive ability was assessed using the testing subset of data. Both manual and automated methods were employed for descriptor selection. Sensitivity analysis of inputs was employed to identify the significance of individual descriptors and to select descriptors that were considered the most important. Descriptors with sensitivities lower than one were regarded as detrimental to the model performance. Hence, the higher the sensitivity, the greater the influence is on the model. Those with lower sensitivities were able to be sequentially removed.

\subsubsection{Genetic Programming (GP) Model}

GP, which is a derivate of the genetic algorithm (GA) paradigm, is one of the evolutionary computation (EC) algorithms in computational intelligence [18]. GP evolves regression models based on the Darwinian principle of natural selection. Evolutionary processes include reproduction, duplication, elimination, and mutation. GP can identify the importance of each input parameter, and can also provide the structure of the resulting functions transparently. GP has received wide attention and has been used to derive non-linear regression models for a variety of environmental applications [21][23][24] [25].

In this study, linear genetic programming (LGP), which is an extension of the GP family, was applied. The LGP expresses instructions in a line-by-line mode. Execution of the program is a mimic of calculating multiple calculations through a series of simple line-by-line processing steps in a normal calculator. In this study, the GP software package Discipulus $®$ [26], was applied. The codes are defined in term of functions and terminal sets that modify the contents of internal memory and program counter. Discipulus ${ }^{\circledR}$ uses LGP algorithms to produce multiple lists of instructions representing models with the best fit to its datasets for training and calibration, respectively [26]. Each combination of differing datasets would aid in determining the relative importance of reflectance across different wavelengths and environmental impacts [26]. 


\subsection{Information retrieval}

MODIS datasets are delivered as "Base Level Swath Data" as well as "gridded data". Grid data were generated in either Intergerized Sinusoidal (ISIN, Level V2003) or Sinusoidal (SIN, Level V004) projections. Both data types require further preprocessing before they can be used in a GIS environment, especially for ISIN that is usually unsupported in most of "off the shelf" and free GIS and image processing software. The "MODIS Reprojection Tool (MRT) can be used to reproject both ISIN and SIN to a more common projection (e.g. UTM). Furthermore, MRT allows for geographical subsetting. It writes the output to standard data formats such as Geo TIFF, and is executable on various operating systems. Therefore, in this study, two years of MODIS data were processed by MRT software for the GIS usage.

The geographical locations of monitoring stations were imported into a GIS map layer and the values of the MODIS images were extracted by using the GRID SPOT function in ARCMAP9. ${ }^{\circledR}$. The MODIS pixel values include some of the surface reflectance bands 1 to 7 and synchronous in-situ turbidity data were collected for calibration and validation. The whole data were thus separated randomly into three datasets based on a two-year time series. The first and second datasets were used for model calibration and the third for model validation. In order to have the same comparative basis, all three types of models are derived based on the same 11 variables.

\subsection{Assessment criteria for model selection}

In any circumstances, it is necessary to have ways to evaluate the developed modes based on their performance. Several methods for evaluating the credibility of turbidity prediction have been summarized [27]. In principle, a good model should offer the least differences between the predicted turbidity and the observed turbidity. The four statistical parameters applied in this case study to enable a fair comparison of the model, are described below.

\subsubsection{Root-mean-square error (RMSE):}

The RMSE indicates a better model as its value approaches zero.

$$
R M S E=\sqrt{\frac{\sum_{i=1}^{n} S E}{N}}
$$

where the sum of errors (SE) is the difference between values predicted by a model or an estimator and the values actually observed from the object modeled or estimated. $\mathrm{N}$ is the total number of data points involved

\subsubsection{Ratio of standard deviation of predicted to observed values:}

The ratio of standard deviation of predicted and observed turbidity indicates a better model as it approaches 1 .

$$
C O=\sqrt{\frac{\sum\left(y_{f}-\overline{y_{f}}\right)^{2}}{\sum\left(y_{o}-\overline{y_{o}}\right)^{2}}}
$$

where $y_{f}$ is the predicted turbidity value, $\overline{y_{f}}$ is the mean of the predicted turbidity value. $y_{o}$ is the observed turbidity value, $\bar{y}_{o}$ is the mean of the observed turbidity value. The bar above each parameter indicates the arithmetic mean.

\subsubsection{Mean of percent error (PE):}

The PE indicates a better model when its value approaches zero. 


$$
P . E .=\frac{\sum_{N}\left[\frac{\left(y_{f}-y_{o}\right)}{y_{o}} 100 \%\right]}{N}
$$

where $y_{f}$ is the predicted turbidity value, $y_{o}$ is the observed turbidity value, $\mathrm{N}$ is the total number of data points involved.

\subsubsection{Square of the Pearson product moment correlation coefficient:}

The square of the Pearson product moment correlation coefficient indicates a better model as it approaches 1 .

$$
r^{2}=\left[\frac{\sum\left(y_{o}-\overline{y_{o}}\right)\left(y_{f}-\overline{y_{f}}\right)}{\sqrt{\sum\left(y_{o}-\overline{y_{o}}\right)^{2} \sum\left(y_{f}-\overline{y_{f}}\right)^{2}}}\right]^{2}
$$

where $y_{f}$ is the predicted turbidity value, $y_{o}$ is the observed turbidity value.

\section{RESULTS AND DISCUSSION}

\subsection{MNR model}

The R square value indicates the proportion of the variance in the criterion variable which is accounted for by our model. The regression coefficients were determined by SPSS ${ }^{\circledR}$ software. The MNR model produced $\mathrm{R}^{2}$ values of 0.43 and 0.15 in model calibration and validation, respectively. The final model can be expressed below:

$$
\begin{aligned}
& \text { Turbidity }=-93.74+0.24 \times \mathrm{b} 1+7.96 \times 10^{-8} \times \mathrm{b} 1^{3}+-0.49 \times \mathrm{b} 2 \div(-3.04+\mathrm{b} 2)+0.22 \times \mathrm{b} 3 \div \\
& (75.61+\mathrm{b} 3)+0.22 \times \mathrm{b} 4 \div(92.92+\mathrm{b} 4)+-0.21 \times \mathrm{b} 6 \div(-24.05+\mathrm{b} 6)+2.50 \times 10^{4} \times \text { temp } \div(- \\
& 1.23+\text { temp })+2.48 \times 10^{4} \times \text { wind } \div(-8.14+\text { wind })+9.53 \times 10^{3} \times \text { level } \div\left(1.52 \times 10^{3}+\text { level }\right)
\end{aligned}
$$

Table 3 lists all estimated regression coefficients. The magnitude of these coefficients gives a measure of the contribution associated with each variable in the model (i.e. marginal effect). A large value indicates that a unit change of this predictor may have a larger impact than the others on the turbidity estimation. The $95 \%$ confidence interval associated with each coefficient reveals information as to whether or not the corresponding regression coefficient is statistically significant. If so, the possible range in variation may be inferred by the statistics.

\subsection{ANN model and sensitivity analysis}

All 317 descriptors generated with 2003 and 2004 data were used to train the ANN. The final model was selected by STISTISTICA ${ }^{\circledR}$ based on the produced $\mathrm{R}^{2}$ values of 0.62 and 0.4 in model calibration and validation, respectively. The adopted ANN model was able to identify water level, air temperature, wind speed, and MODIS bands 1, 3, 4, 6, and 7 as influential factors. The importance of the input variables was further examined by using the sensitivity analysis provided in the STATISTICA ${ }^{\circledR}$ Neural Networks module. Sensitivity analysis often identifies variables that can safely be ignored or key variables that can be retained. Moreover, the key variables are always of high sensitivity; others are of low sensitivity and ambiguous variables change their ranking slightly. Table 4 presents the result of sensitivity analysis. In 
this table, the highest ratio is wind speed (1.000429), the second one is Band 1 of MODIS (1.000045), and the third one is Band 4 (0.999993). This finding is consistent with our knowledge that Band 1 and wind speed are relatively more important than the others in influencing the turbidity identification. Yet the adopted ANN model does not seem to have salient differentiation over those 8 explanatory variables in terms of ration in Table 4 . This could be partially due to that the datasets used for validation of the ANN model are not more than enough. In order not to end up overfitting of the training model, the issue can not be ameliorated.

Table 3. Table of coefficients used in equation (6)

\begin{tabular}{|c|c|c|c|}
\hline \multirow{2}{*}{ Variable } & \multirow{2}{*}{ Coefficient } & \multicolumn{2}{|c|}{$95 \%$ confidence interval } \\
\cline { 3 - 4 } & -93.74 & -426.19 & Upper bound \\
\hline $\mathrm{a}_{0}$ & 0.24 & 0.17 & 238.70 \\
\hline $\mathrm{a}_{1}$ & $7.96 \times 10^{-8}$ & $3.44 \times 10^{-8}$ & 0.31 \\
\hline $\mathrm{a}_{2}$ & -0.49 & -38.91 & $3.24 \times 10^{6}$ \\
\hline $\mathrm{a}_{3}$ & -3.04 & -6.72 & 0.63 \\
\hline $\mathrm{a}_{4}$ & 0.22 & -0.17 & 0.61 \\
\hline $\mathrm{a}_{5}$ & -75.61 & -78.70 & -72.53 \\
\hline $\mathrm{a}_{6}$ & 0.22 & -1.17 & 1.63 \\
\hline $\mathrm{a}_{7}$ & -92.91 & -115.10 & -70.73 \\
\hline $\mathrm{a}_{8}$ & $9.53 \times 10^{3}$ & $-2.87 \times 10^{6}$ & $2.88 \times 10^{6}$ \\
\hline $\mathrm{a}_{9}$ & $1.52 \times 10^{3}$ & $-4.68 \times 10^{5}$ & $4.71 \times 10^{5}$ \\
\hline $\mathrm{a}_{10}$ & -0.21 & -1.70 & 1.27 \\
\hline $\mathrm{a}_{11}$ & -24.05 & -24.40 & -23.69 \\
\hline $\mathrm{a}_{12}$ & $2.54 \times 10^{4}$ & $-3.795 \times 10^{7}$ & $3.80 \times 10^{7}$ \\
\hline $\mathrm{a}_{13}$ & $-1.23 \times 10^{4}$ & $-1.84 \times 10^{7}$ & $1.83 \times 10^{7}$ \\
\hline $\mathrm{a}_{14}$ & $-2.48 \times 10^{4}$ & $-2.93 \times 10^{7}$ & $2.93 \times 10^{7}$ \\
\hline $\mathrm{a}_{15}$ & $-8.14 \times 10^{3}$ & $-9.60 \times 10^{7}$ & $9.59 \times 10^{7}$ \\
\hline $\mathrm{a}_{16}$ & & & \\
\hline
\end{tabular}

\subsection{GP model}

Presently available computational power normally in desktop computers enables the derivation of highly complex non-linear functions via GP models for estimating the turbidity. In our study, millions of GP-based models were created, measured, and assessed during the evolutionary process. The better the fitness value, the better the model. To get a better result, we had already generated evidence that many GP-derived models could be rejected due to either over- or poor fitting. As for the over-fitting, less-complex structured models may have a better chance to survive to the final selection. Only the top 30 models with the highest level of fitting were selected for further evaluation.

Amongst the top 30 models, the best model based on the fitness of the training data may not perform well in cases based on the unseen data. Therefore, the GP model that performed well on both the calibration and unseen datasets was finally chosen in this study. The fitness 
of GP-derived models can be further identified by both $\mathrm{R}^{2}$ and $\mathrm{t}$-score statistics based on the unseen datasets from which the best GP-derived model of turbidity was chosen.

Table 4. Sensitivity analysis derived from the ANN model

\begin{tabular}{|c|c|c|}
\hline Input & Ration & Rank \\
\hline Band 1 & 1.000045 & 2 \\
\hline Band 3 & 0.999988 & 4 \\
\hline Band 4 & 0.999993 & 3 \\
\hline Band 6 & 0.999744 & 8 \\
\hline Band 7 & 0.999830 & 6 \\
\hline Water level & 0.999777 & 7 \\
\hline Air temperature & 0.999981 & 5 \\
\hline Wind speed & 1.000428 & 1 \\
\hline
\end{tabular}

The computational time necessary create a GP-derived model depends on many factors such as the amount of input data, the number of variables, or the complexity of functions. In this study, it normally took 30-60 min to derive a full-scale GP model based on the 317 datasets. Initially, the ground truthing turbidity, wind speed, water level, rainfall, air temperature, and the MODIS scale from bands 1 to 7 were established as independent variables that were used as inputs to calibrate the GP models in the evolutionary process. Findings indicate that the best GP model derived from the 317 datasets can be depicted as in Eq. (7). It produced $\mathrm{R}^{2}$ values of 0.64 and 0.55 in model calibration and validation, respectively.

Hence, the turbidity forecasting model, which is a series of convoluted functions in algebra, can be expressed as below:

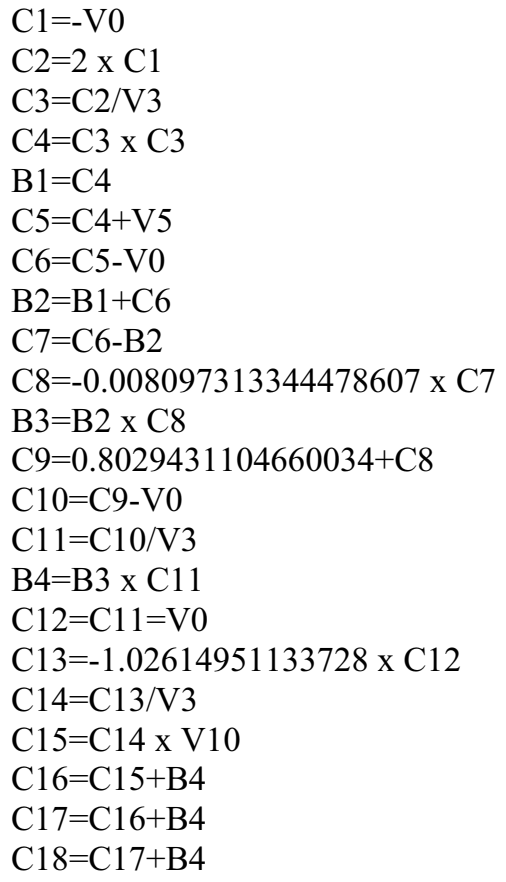

Equation (7) can actually be transformed into a single equation with a highly nonlinear functional form if all the convoluted functions may be superimposed together. Yet this is not an easy way to recognize the nonlinear structure. Frequency of use (FOU), a statistical index, 
is defined by the GP evolutionary process to measure how often an input variable is used during the calibration of a GP-derived model. It is literally an objective measurement that indicates a relative importance across all input variables. A higher percentage of FOU of input variable may show that the variable is more relevant to the underlying theory of a prescribed model. Therefore, Table 5 summarizes the FOU of all input variables for the top 20 models selected by the GP-based evolutionary process. One of the most interesting findings was that wind speed (i.e., 100\%) and Band 1 of MODIS satellite image were the most important factors in determining turbidity values.

Table 5. Inputs for the frequency analysis

\begin{tabular}{|c|c|c|}
\hline Input & Description & Frequency \\
\hline V0 & Band 1 & 1.00 \\
\hline V1 & Band 2 & 0.03 \\
\hline V2 & Band 3 & 0.60 \\
\hline V3 & Band 4 & 0.53 \\
\hline V4 & Band 5 & 0.03 \\
\hline V5 & Band 6 & 0.93 \\
\hline V6 & Band 7 & 0.03 \\
\hline V7 & Water level & 0.43 \\
\hline V8 & Air temperature & 0.50 \\
\hline V9 & Rainfall & 0.03 \\
\hline V10 & Wind speed & 1.00 \\
\hline
\end{tabular}

\subsection{Comparative assessment of model advantages}

First, in-situ data for October 13, 2003 were used for model comparison. Figure 3 presents the comparison of model performance. The training datasets are part of the available datasets that were used for model calibration and the unseen datasets are those being used for model validation. The trends reveal that GP is, in relation to the others, the best model. Obviously, the MNR model shows higher inaccuracy among all three models. For a quantitative comparison of the model performance, Table 6 summarizes the statistical performance of three models versus four criteria simultaneously. With regard to the criterion of PE, the GP model performance is the best. As for the R-square value, the ANN model performance is the best. When looking at the CO and RMSE, the GP model outperforms all others. Overall, we consider the model derived by the GP algorithm to be the most suitable for lake turbidity estimation. This finding is also consistent with the literature when taking the soil moisture content into account [23].

\subsection{Turbidity maps and the hurricane effect}

Table 7 shows hurricanes in South Florida in 2003 and 2004 in which Ivan was quite distant in the Gulf of Mexico, so that this study discusses only on the remaining three. When a hurricane passed over the lake, strong currents and wind-driven waves were generated that ran perpendicular to the shorelines and caused uprooting of submerged and merged plants. During Hurricanes Frances and Jeanne, the north and south seiches with water level differences at 2 and $3 \mathrm{~m}$ piled up large amounts of detritus and uprooted aquatic vegetation on the north and south lake shore. As a consequence, hurricanes may have transported a large amount of fine mud sediments to the shoreline regions. The in-situ turbidity data measured before and after hurricane events (Figure 4) confirmed this hypothesis. The impact on turbidity changes after Hurricane Frances is elaborated in the following discussion. 
Table 6. Summary of statistical performance of the MNR, GP and ANN models against four quality

\begin{tabular}{|c|c|c|c|}
\hline & validation indices \\
\hline PE & 514.64 & 438.78 & 533.67 \\
\hline R-Square & 0.30 & 0.42 & 0.46 \\
\hline CO & 7.40 & 2.20 & 3.71 \\
\hline RMSE & 22.20 & 6.61 & 11.13 \\
\hline
\end{tabular}

Due to the shallow depths of Lake Okeechobee, bottom stresses from wind-generated surface waves are considered to be the major cause of sediment resuspension and transport leading to the observed large increase in turbidity levels. When Hurricanes Frances and Jeanne arrived in September 2004, the in-situ turbidity increased immediately after they passed over the Lake. For example, the turbidity at site L006 increased from 18.5 NTU to 64.8 NTU and continued to increase up to 232 NTU. Moreover, the turbidity at site L005 increased from 9.8 NTU to 66.4 NTU; the highest turbidity increase was 176 NTU. Similarly, the turbidity at site LZ40 varied from 31.7 NTU to 150 NTU with the highest increase of 178 NTU. In contrast, the turbidity at site L001 decreased from 35.3 NTU to 12.9 NTU but increased in November and December.

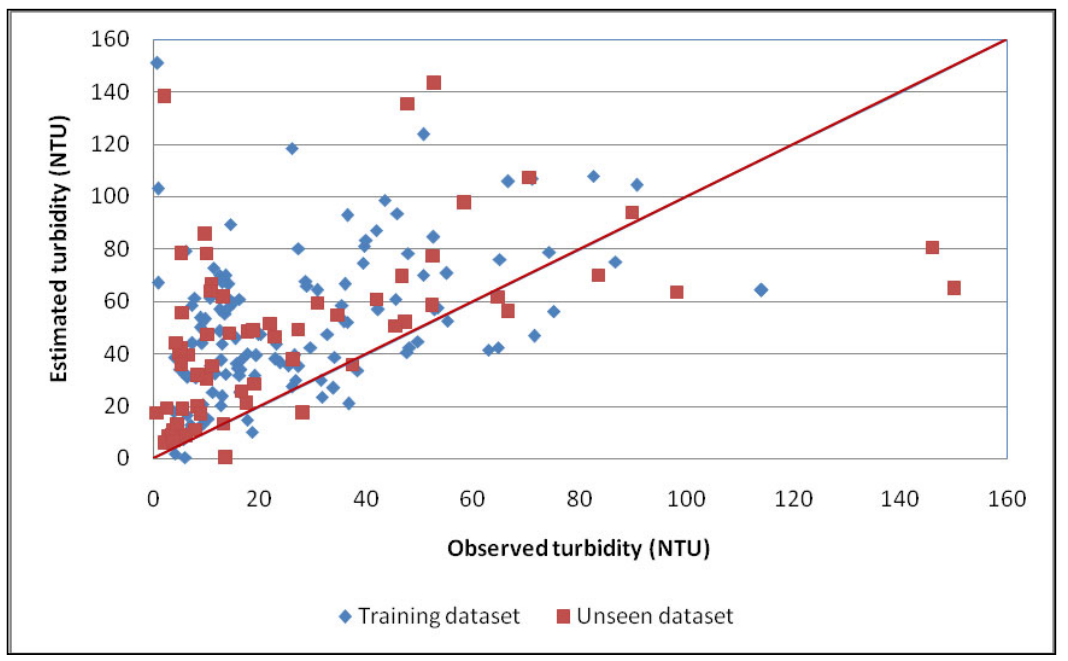

3(a) Non-linear regression model 


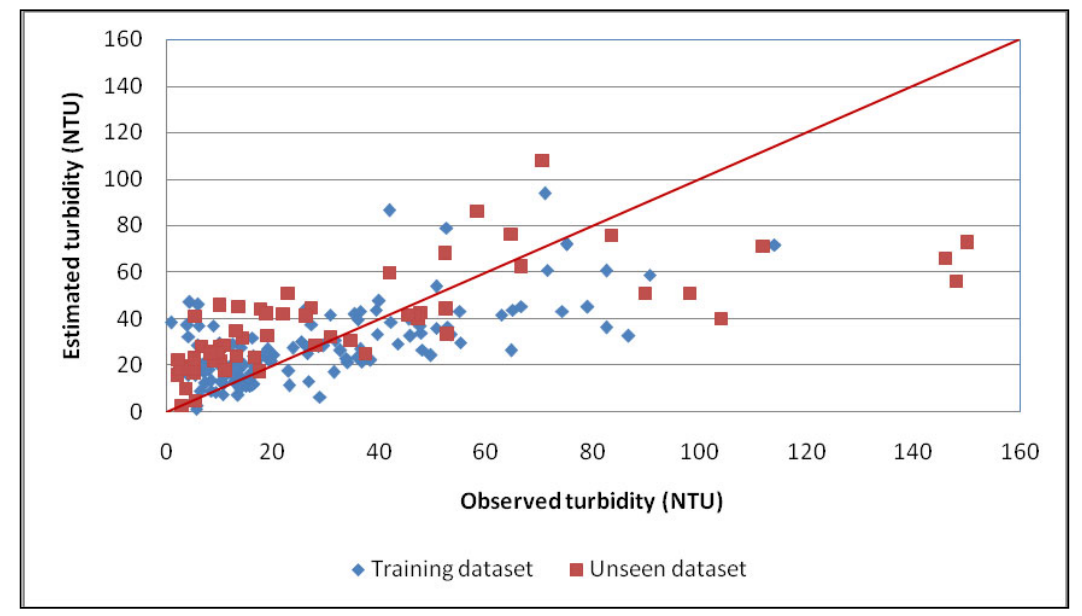

3(b) Artificial neural networks (ANN) model

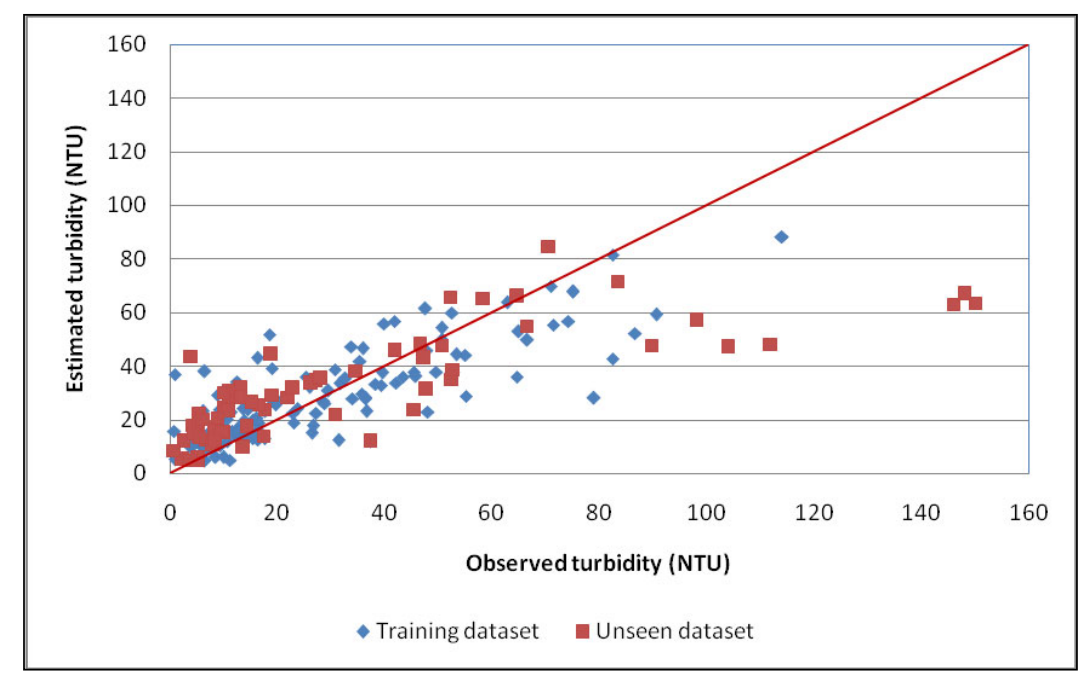

3(c) Genetic programming (GP) model

Fig. 3. Observed vs. modeled turbidity levels: comparison of model performance in Lake Okeechobee.

To understand the mechanisms of the course of turbidity and transport, satellite images were used to track their spatiotemporal variations. Because the GP algorithm offers the best model performance, it was selected for the tracking and assessment. The following turbidity maps before and after hurricane Francis were generated using the selected GP model. Figure 5 shows turbidity map on August 9, 2004, displaying the higher turbidities at the central and southern parts of the Lake when compared to the average turbidity of 9.49 NTU. Figure 6 shows the reconstructed turbidity maps after the hurricane events (Francis and Jeanne) on October 11th, 2004. At that time, the strong wind stirred up the water column and the lake bottom mud was resuspended and transported to the lake's surface. The resulting average turbidity was $27.55 \mathrm{NTU}$, three times higher than the average turbidity 9.49 NTU in the prehurricane monitoring period. Figure 7 shows the turbidity map on November 18th, 2004 after 
the hurricane, which is further evidence of large scale turbidity transport. For example, the higher turbidity appeared at the northeast and central parts of the lake. The in-situ turbidity measurement data from site L001 also increased from 12.9 NTU to 98.1 NTU; this result is consistent with the remotely-sensed turbidity map based on our GP model. The average turbidity was $26.01 \mathrm{NTU}$ - much higher than the pre-hurricane turbidity level.

Table 7. Details of 2004 and 2005 Hurricanes affecting Lake Okeechobee. Source: SFWMD (2008).

\begin{tabular}{|c|c|c|c|c|c|c|}
\hline Storm & Category & Date & Year & $\begin{array}{c}\text { Landfall } \\
\text { Location }\end{array}$ & $\begin{array}{c}\text { Max Wind } \\
\text { Speed } \\
\left(\mathrm{Km} \mathrm{hr}^{-1}\right)\end{array}$ & $\begin{array}{c}\text { Persistent Time } \\
(\text { Days })>8 \mathrm{~m} \mathrm{~s}^{-1}\end{array}$ \\
\hline Ivan & 3 & $16-$ Sep & 2004 & $\begin{array}{c}\text { Gulf } \\
\text { Shores, } \\
\text { Alabama }\end{array}$ & 83 & 2.3 \\
\hline Frances & 4 & $24-$ Aug & 2004 & Cat Island & 107 & 4.7 \\
\hline Jeanne & 3 & $26-$ Sep & 2004 & $\begin{array}{c}\text { Hutchinson } \\
\text { Island }\end{array}$ & 118 & 2.5 \\
\hline Wilma & 3 & $24-$-Oct & 2005 & $\begin{array}{c}\text { Cape } \\
\text { Romano }\end{array}$ & 146 & 1.5 \\
\hline
\end{tabular}

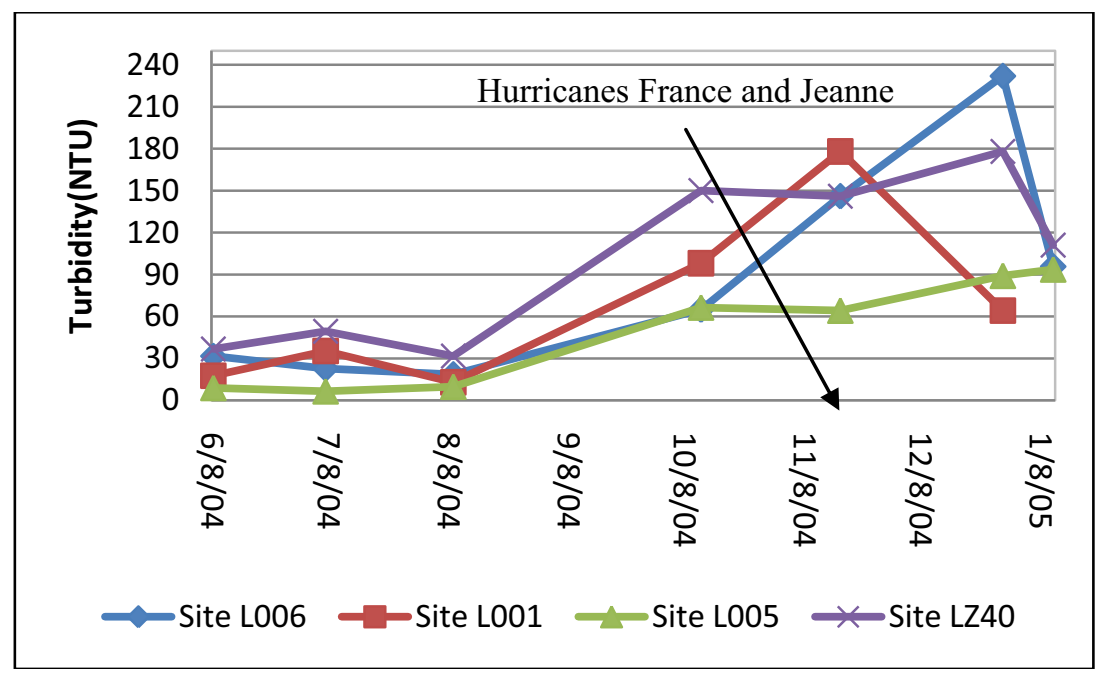

Fig. 4. Temporal variations of the in-situ turbidities before and after hurricane France and Jeanne 


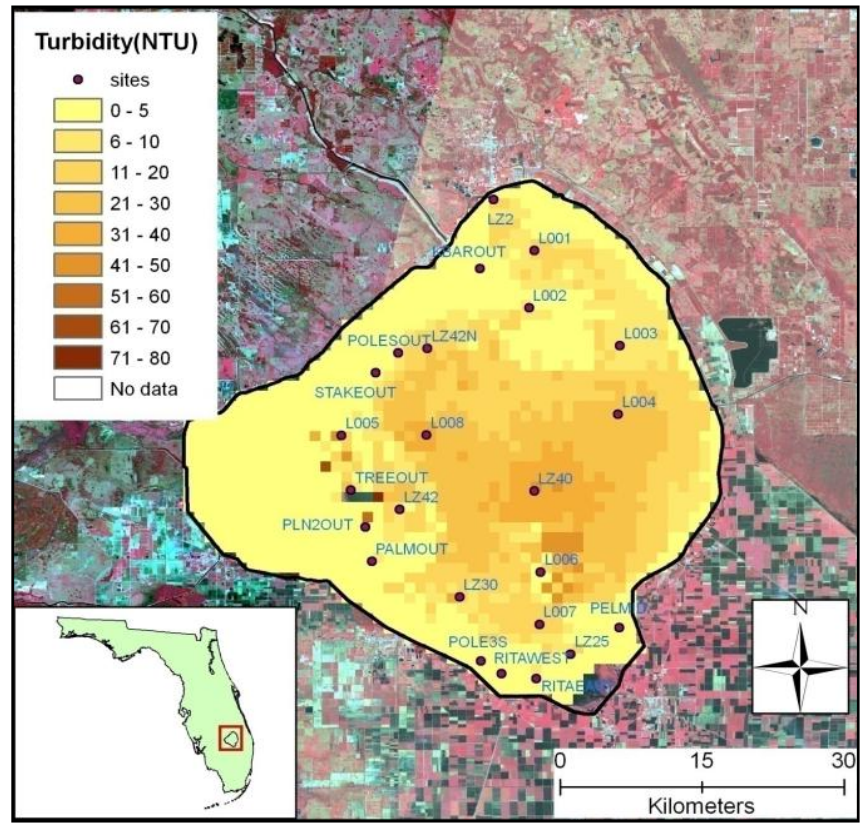

Fig. 5. Turbidity map (GP Model) in Lake Okeechobee on August 9th, 2004 before landfall of Hurricane Francis.

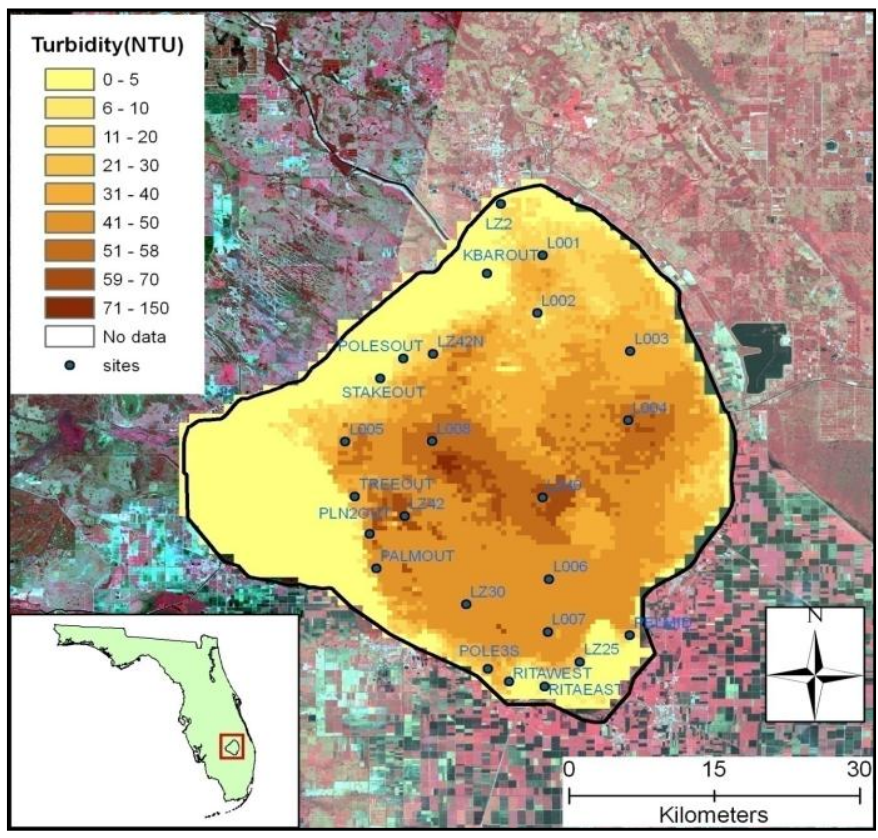

Fig. 6. Turbidity map (GP Model) in Lake Okeechobee on October 11th, 2004, 15 days after Hurricane Jeanne. 


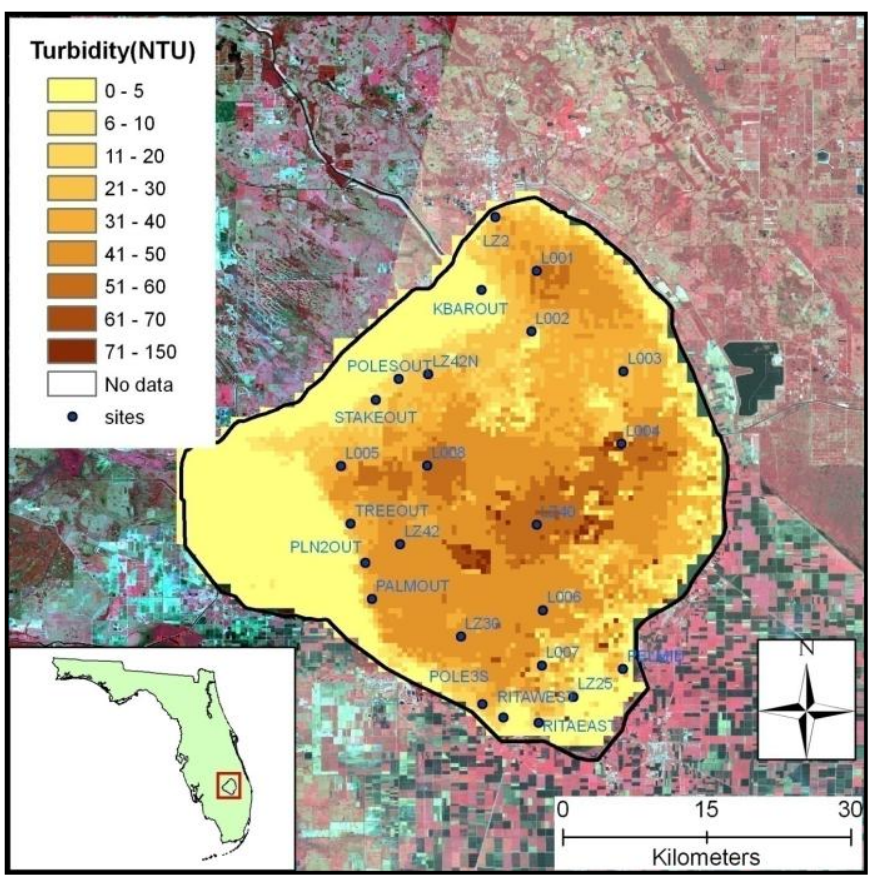

Fig. 7. Turbidity map (GP model) in Lake Okeechobee on November 18, 2004, 53 days after Hurricane Jeanne.

Overall, Lake Okeechobee is a big and shallow lake and the energy absorbed through the wind during the hurricane events was only gradually released after the landfalls. It follows the sequence that the wind energy disturbs the lake water at first, weaken the sediment layer at the bottom gradually, and release the suspended solid via a resuspension process. It leads to a successive time lag as the TSS concentrations increase over time after the events as the lake hydrodynamic patterns drive the TSS across the surface of the lake. Spatially, based on the bisymmetry, western part of the lake where littoral zone dominates over the pelagic among most standing water ecosystems has very shallow water depth and thin sediment layer ending up relatively lower TSS concentrations always.

\section{CONCLUSIONS}

In this study, the performance of three data mining models, including empirical regression, neural network, and genetic programming, was compared systematically in terms of turbidity reconstruction based on the four statistical measures described. The non-linear GP model was identified as the most appropriate to reconstruct spatiotemporal maps of the turbidity using the MODIS data and a few meteorological parameters in Lake Okeechobee, Florida. The spatiotemporal turbidity patterns reveal an increasing trend of turbidity across the central part of the lake after the hurricanes. Probably arising from the shallow depth of the lake, the derived turbidity changes strongly indicate that fine mud at the bottom of the lake was stirred up by strong winds during the hurricane events, resulting in significant increase of the turbidity level across the lake. Hydrodynamic circulation within the lake drives the total suspended solid around the mud zone accounting for partial deposition and transport processes.

The remote sensing data show a substantial migration of mud at the bottom of the lake toward the shorelines during the hurricane events. The implications of this sediment transport on the ecology and water quality could be significant because of the high phosphorus loads in 
the lake sediments. Re-suspension of these sediments and the dissolution of phosphorus into aqueous phase may cause growth stimulation of cattail or algal bloom along the lake's perimeter after the hurricane events. This will probably become especially noticeable if the increasing trend of turbidity fails to significantly hinder the light penetration needed for plankton growth and the wind-induced shearing stress during the hurricane events was subdued. Further quantitative assessment in the intertwined factors between hurricane events, hydrodynamic fields of the lake, nutrient-laden sediment migrations, and post-event ecological changes can be warranted as long as the TSS distribution patterns are consistent with the outputs from Lake Okeechobee Environment Model (LOEM). Nonetheless, with the aid of remote sensing images and the GP model, the visualized turbidity maps may be used to support ecosystem modeling for improved decision-making in lake water quality management and ecosystem conservation.

\section{Acknowledgments}

Financial and administrative support from the US EPA National Risk Management Research Laboratory and South Florida Water Management District is gratefully acknowledged. The U.S. Environmental Protection Agency, through its Office of Research and Development, funded and managed, or partially funded and collaborated in, the research described herein. It has been subjected to the Agency's administrative review and has been approved for external publication. Any opinions expressed in this paper are those of the author(s) and do not necessarily reflect the views of the Agency; therefore, no official endorsement should be inferred. Any mention of trade names or commercial products does not constitute endorsement or recommendation for use.

\section{References}

[1] P. A. J. Moore, K. R. Reddy, and M. M. Fisher, "Phosphorus flux between sediment and overlying water in Lake Okeechobee, Florida: spatial and temporal variations," $J$. Environ. Qual. 27, 1428-1439 (1998).

[2] M. M. Fisher, K. R. Reddy, and R. T. James, "Internal nutrient loads from sediments in a shallow, subtropical Lake," Lake and Reservoir Management 21, 338-349 (2005) [doi:10.1080/07438140509354439].

[3] V. D. Klemas, W. P. Bartlett, and R. Roger, "Coastal and estuarine studies with ERTS-1 and Skyla," Rem. Sens. Environ. 3, 153-177 (1974).

[4] R. Stumpf and J. Pennock, "Calibration of a general optical equation for remote sensing of suspended sediments in a moderately turbid estuary," J. Geophys. Res. 94(C10), 14,363-14,371 (1989) [doi:10.1029/JC094iC10p14363].

[5] M. D. Nellis, J. A. Harrington Jr., and J. P. Wu, "Remote sensing of temporal and spatial variations in pool size, suspended sediment, turbidity, and Secchi depth in Tuttle Creek Reservoir, Kansas: 1993," Geomorphology 21, 281-293 (1998) [doi:10.1016/S0169-555X(97)00067-6].

[6] L. E. Keiner and X. H. Yan, "A neural network model for estimating sea surface chlorophyll and sediments from Thematic Mapper Imagery," Rem. Sens. Environ. 66, 153-165 (1998) [doi:10.1016/S0034-4257(98)00054-6].

[7] A. G. Dekker, R. J. Vos, and S. W. M. Peters, "Comparison of remote sensing data, model results and in situ data for total suspended matter (TSM) in the southern Frisian lakes," Sci. Total Environ. 268(1-3), 197-214 (2001) [doi:10.1016/S00489697(00)00679-3]. 
[8] P. Harma, J. Vepsalainen, T. Hannonen, T. Pyhalahti, J. K"amari, K. Kallio, K. Eloheimo, and S. Koponen, "Detection of water quality using simulated satellite data and semi-empirical algorithms in Finland," Sci. Total Environ. 268, 107-121 (2001) [doi:10.1016/S0048-9697(00)00688-4].

[9] S. Koponen, J. Pulliainen, K. Kallio, and M. Hallikainen, "Lake water quality classification with airborne hyperspectral spectrometer and simulated MERIS data," Rem. Sens. Environ. 79, 51- 59 (2002) [doi:10.1016/S0034-4257(01)00238-3].

[10] Z. Q. Chen, F. E. Muller-Karger, and C. M. Hu, "Remote sensing of water clarity in Tampa Bay," Rem. Sens. Environ. 109(2), 249-259 (2007) [doi:10.1016/j.rse.2007.01.002].

[11] Z. Q. Chen, C. M. Hu, and F. E. Muller-Karger, "Monitoring turbidity in Tampa Bay using MODIS/Aqua 250-m imagery," Rem. Sens. Environ. 109(2), 207-220 (2007) [doi:10.1016/j.rse.2006.12.019].

[12] D. G. Zawada, C. M. Hu, T. Clayton, Z. Q. Chen, J.C. Brock, and F. E. Muller-Karger, "Remote sensing of particle backscattering in Chesapeake Bay: A 6-year SeaWiFS retrospective view," Estuarine, Coastal and Shelf Science 73, 792-806 (2007) [doi:10.1016/j.ecss.2007.03.005].

[13] J. D. Shutler, P. E. Land, T. J. Smyth, and S. B. Groom, "Extending the MODIS $1 \mathrm{~km}$ ocean colour atmospheric correction to the MODIS $500 \mathrm{~m}$ bands and $500 \mathrm{~m}$ chlorophyll-a estimation towards coastal and estuarine monitoring," Rem. Sens. Environ. 107, 521-532 (2007) [doi:10.1016/j.rse.2006.10.004].

[14] P. H. Cabena, R. Stadler, J. Verhees, and A. Zanasi, Discovering data mining: from concept to implementation, IBM, New Jersey (1998).

[15] R. Groth, Data Mining: A Hands-on Approach for Business Professionals, Prentice Hall Inc., New Jersey (1998).

[16] F. Rosenblatt, Principles of Neurodynamics, Sparton Books, Washington, DC (1962).

[17] E. Bienenstock, F., F. Fogelman-Soulie, and G. Weisbuch, Eds, "Learning Processes in an Asymmetric Threshold Network," In Disordered Systems and Biological Organization, pp. 233-240, Les Houches, France (1986).

[18] J. R. Koza, "Genetic Programming: On the Programming of Computers by Means of Natural Selection," MIT Press, Cambridge, MA, USA (1992).

[19] E. J. Hannan, "Non-linear Time Series Regression," Applied Probability Trust, 767-780 (1971).

[20] J. V. Turner, D. J. Maddalena, and D. J. Cutler, "Pharmacokinetic parameter prediction from drug structure using artificial neural networks," Int. J. Pharm. 270(1-2), 209-219 (2004) [doi:10.1016/j.ijpharm.2003.10.011].

[21] X. Chen, S. L. Yok, L. Zhigang, Y. Kedong, L. Zhilin, W. W. Onyx, and K. Bruce, "Integration of multi-source data for water quality classification in the Pearl River estuary and its adjacent coastal waters of Hong Kong," Continen. Shelf Res. 24, 18271843 (2004) [doi:10.1016/j.csr.2004.06.010].

[22] StatSoft Inc., "Statistica software," 2000, <http://www.statsoft.com/?kw= statistical\%20analysis\&gclid=COGh4f525UCFQRhswodDS6VDQ $>$.

[23] A. Makkeasorn, N. B. Chang, M. Beaman, C. Wyatt, and C. Slater, "Soil moisture estimation in a semiarid watershed using RADARSAT-1 satellite imagery and genetic programming," Water Resour. Res. 42, 1-15 (2006) [doi:10.1029/2005WR004033].

[24] N. Muttil and K.W. Chau, "Neural network and genetic programming for modeling coastal algal blooms," Int. J. Environ. Pollut. 28(3), 223-238 (2006) [doi:10.1504/IJEP.2006.011208].

[25] A. Makkeasorn, N. B. Chang, and X. Zhou, "Short-term streamflow forecasting with global climate change implications - A comparative study between genetic programming and neural network models," J. Hydrol. 352, 336-354 (2008). 
[26] F. D. Francone, Discipulus ${ }^{\mathrm{TM}}$ Software Owner's Manual version 3.0 DRAFT, Machine Learning Technologies, Inc. (1998).

[27] K. W. Hipel, A. I. McLeod, U. S. Panu, and V. P. Singh, Eds., Stochastic and statistical methods in hydrology and environmental engineering 3, 77-85 (1994). 